\title{
In the eye of a tropical cyclone
}

\section{Carlo Buontempo ${ }^{1}$ * Harald Flentje ${ }^{2 * *}$ Christoph Kiemle ${ }^{2}$}

\author{
${ }^{1}$ Istituto di Scienze dell'Atmosfera e del \\ Clima sez. di Roma/CNR, Rome, Italy \\ 2 Institut für Physik der \\ Atmosphäre/DLR, Oberpfaffenhofen, \\ Germany \\ * Now at the Met Office, Exeter, UK \\ * Now at German Weather Service, \\ Hohenpeissenberg, Germany
}

Disastrous tropical cyclones are a topical issue, particularly because any change in their intensity or frequency is widely recognised as an indicator for an ongoing climate change. They are powered by latent heat release over warm oceans, reflected in their rapid demise after landfall. The prediction of a tropical cyclone's development and track therefore requires precise knowledge of the wind-evaporation interaction, cumulus convection and its up-to-date internal structure (Smith 2000). Further, despite the importance of tropical cyclones for the energy exchange between the tropics and mid-latitudes, it is hard to determine their climatic impact. One of the problems regards the evaluation of the upper-level effect of these storms: little is known on how the cyclones alter the tropopause and on how they interact with the lower tropical stratosphere.

We present the results of an analysis performed for tropical cyclone Davina, a storm that lasted for 20 days and crossed the southern Indian Ocean during late winter 1999. From February to March of the same year an experimental campaign, called APE-THESEO, took place in the western Indian Ocean. It aimed to study the microphysical processes occurring in tropical cirrus and the transport of tracers across the tropical tropopause. To accomplish this task, two aircraft were deployed: the DLR Falcon and the M-55 Geophysica (Fig. 1). Both of them were equipped with a large number of in situ and remote sensing instruments (Stefanutti et al. 2004). The campaign turned out to be potentially important for cyclone research especially after the challenging flight of 9 March. On that day the two airplanes took measurements right above and inside the eye of Davina. Earlier reports of measurements of the internal structure of tropical cyclones at the tropical tropopause level are rare in the literature, moreover the few existing ones are mainly limited to the north Atlantic and to the western Pacific.

\section{Tropical cyclone Davina}

This cyclone formed over the eastern Indian Ocean, south-east of the Maldive Islands on 1 March 1999 (Chan 2002). It had maintained a west-south-west track for most of

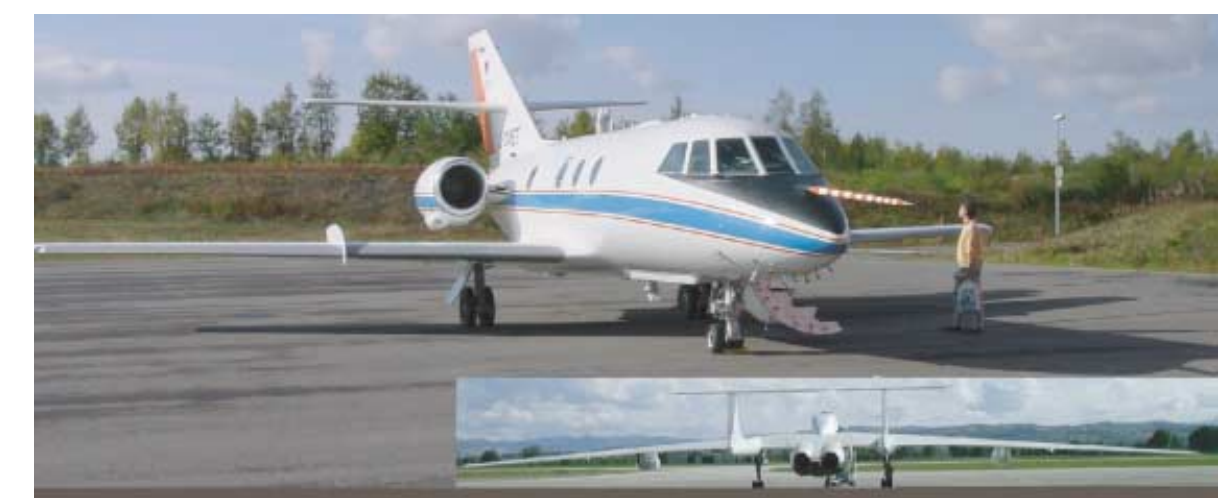

Fig. 1 The two aircraft used during the campaign: the DLR Falcon and (inset) the M55 Geophysica

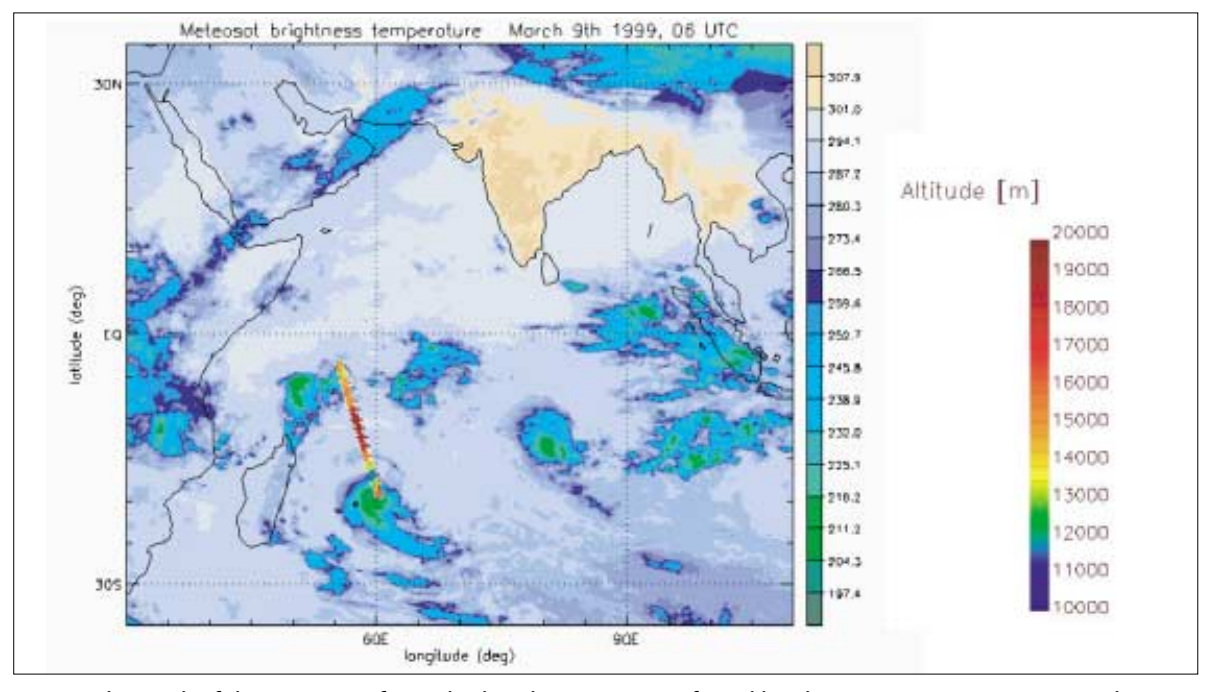

Fig. 2 The track of the two aircraft overlaid to the Meteosat infrared brightness temperature image. The

colour code indicates the flight altitude of the M55 Geophysica with a dip down over the eye wall.

\section{The structure of a tropical cyclone}

Following the definition by the Oxford Dictionary of Weather, a Tropical Cyclone

its life cycle. Davina reached 'Tropical logical Centre, on 5 March 1999. Four days when Davina was experiencing the first at different flight levels, the eye wall of th storm (Fig. 2). Davina began to weaken and on 10 March. It eventually dissipated east of Madagascar on 19 March (Fig. 3). .

Meleosot brighiness temperoture March 9th 1999, 06 UTC 


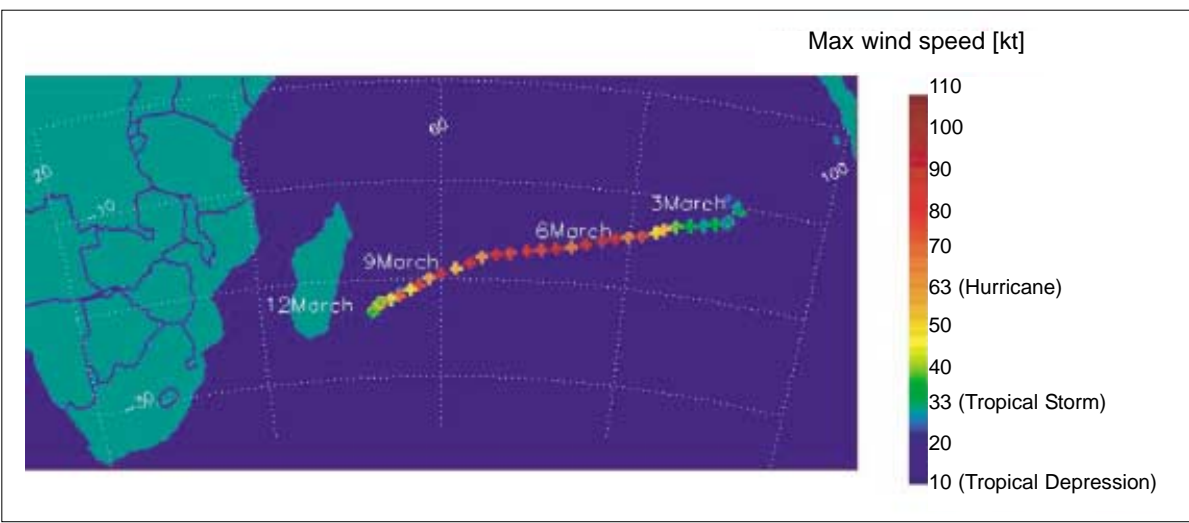

Fig. 3 Track of tropical cyclone Davina (from the Japan Aerospace Exploration Agency, Earth Observation Research and application Centre]

\section{(TC) is:}

"a synoptic-scale, non-frontal, low-pressure system in the tropics or sub-tropics, with maximum sustained wind speeds (1-minute mean) greater than $33 \mathrm{~m} \mathrm{~s}^{-1}$ (62 knots, c. $\left.120 \mathrm{~km} \mathrm{~h}^{-1}\right)$."

\section{(A Dictionary of Weather 2001)}

Although a complete description of the thermodynamics of a tropical cyclone is out of the scope of this paper, it is important here to emphasize some peculiar aspects of these rotating storms (the reader may consult Emanuel (1991; 1999)). The typical structure of a tropical cyclone consists of bands of deep convective cells spiralling towards the centre of low pressure. Around the eye, in a region called the eye wall, the deepest convection is concentrated. Tropical cyclones reach an equilibrium state when the energy production (which is proportional to the wind speed) matches the dissipation due to friction (proportional to the third power of the wind speed). During this steady stage the flow could be considered as an axisymmetric flow spinning cyclonically around the eye except for its uppermost part. In the upper layers, where the circulation is reversed (i.e. flowing anticyclonic around the centre of the storm), large asymmetries due to the interaction with the mean flow are usually occurring. In the case of Davina the outflow jet was curved anticyclonically due to the interaction between the cyclone and the southern subtropical jet.

The strongest convection is concentrated in a ring-shaped region extending from the outer edge of the central eye outward for some tens of kilometres. The maximum updrafts are normally encountered in the uppermost part of the eye wall where a vertical speed up to $10 \mathrm{~m} \mathrm{~s}^{-1}$ is not unusual. Although the cyclone definition that we have adopted does not necessarily imply the presence of an eye, the vast majority of the TCs experience a central cloud-free region at least during their mature stage. In (1) this central part the dry air coming from the uppermost troposphere has been observed to subside gently. This process increases the warm anomaly which is mainly due to latent heat release. This hot core is a typical feature of the tropical cyclone and is particularly pronounced in the upper part of the storm.

In Fig. 4 the observed effect of Davina on the upper tropospheric (equivalent potential) temperature is reported. Cumulonimbus clouds vertically transport a large amount of water in Davina's different phases: water vapour, rain drops, cloud droplets, ice crystals, hailstones, graupel and other ice aggregate. During its developing stage, a TC can generate very intense convection that overshoots its level of neutral buoyancy (the level where the updraft air density is equal to that of the environment) and directly injects moist material in the lower stratosphere. The net results of this process crucially depend on the microphysical processes associated with the particles. The size of the particles is an important parameter. Roughly-speaking Geophysica. small particles tend to evaporate, hydrating the layer while large particles tend to fall causing dehydration.

\section{The instrument}

During the APE-THESEO campaign the 4-wavelength LIDAR (LIght Detection And Ranging) OLEX was installed on board of the DLR research aircraft Falcon 20. This instrument (described by Wirth and Renger 1996) in zenith viewing operation is capable of probing the mid-/upper-tropospheric aerosol distribution along the flight path. It is based on a Nd:YAG laser transmitter and measures the backscatter signal at 1064, 532 and $354 \mathrm{~nm}$ as well as the depolarisation of aspherical particles at $532 \mathrm{~nm}$. Background radiation at small solar zenith angles is suppressed by narrow-band interference filters. The back-scattered photons are collected by a Cassegrain-type telescope with an aperture of $35 \mathrm{~cm}$. The spatial resolution ranges from less than $100 \mathrm{~m}$ horizontally and $10 \mathrm{~m}$ vertically in clouds and dense aerosols to roughly 10 times larger values at free tropospheric conditions.

The penetrable optical depth $\tau$ is limited to $\tau<1-2$, which in infrared was just sufficient to penetrate the eye wall cloud deck of Davina (Fig. 5). For safety reasons, the Davina mission was designed to probe only the outer edge of the cyclone, with measurements of the outer cirrus deck and eventually of the cumulonimbus structures. The two aircraft flew close to each other at their respective cruise altitudes. Approaching the cyclone, the Falcon weather radar monitored no particularly strong turbulent areas, and a break in the cyclone wall was detected. Thus, the Falcon flew

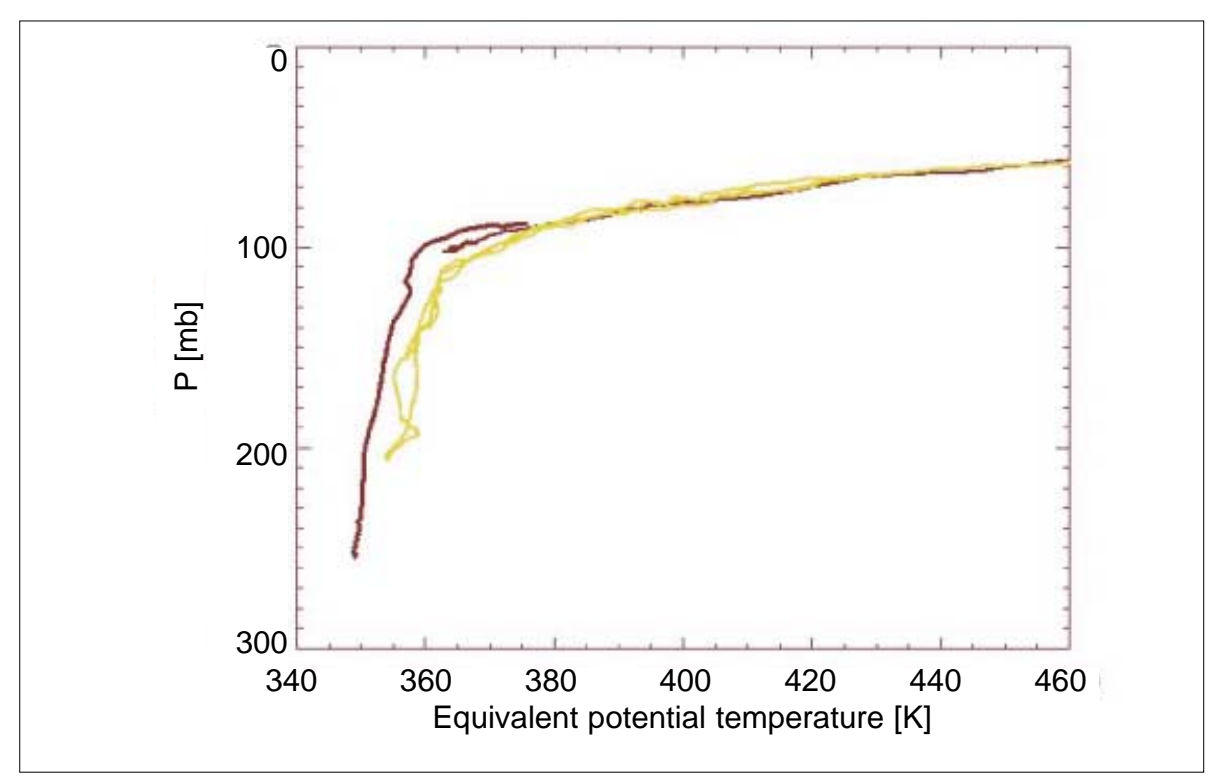

Fig. 4 The equivalent potential temperature above the storm (green line) compared with the profile measured during the take-off and the landing of the plane (brown line). The equivalent potential temperature has been calculated using the total water mixing ratio measured by the fast hygrometer FISH on board of the 


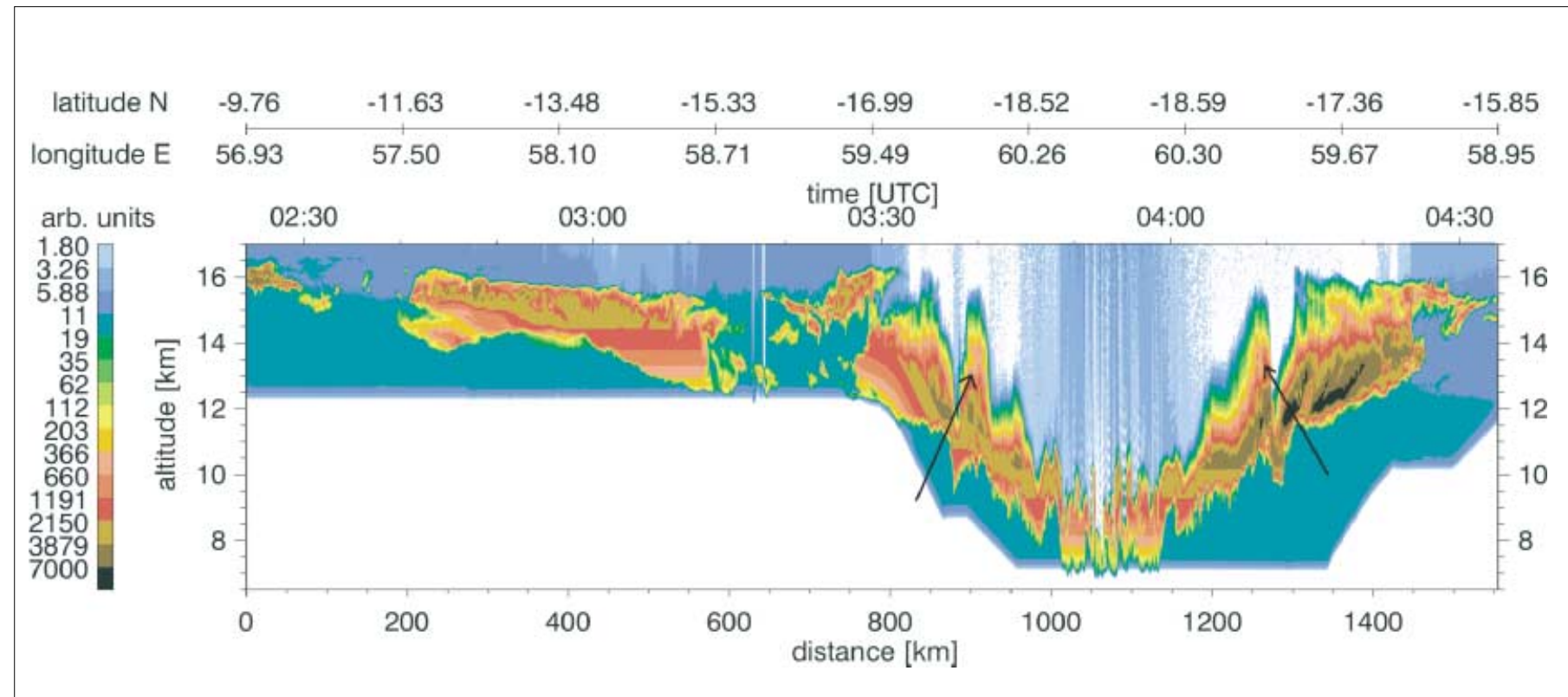

Fig. 5 Backscatter Intensity at $1064 \mathrm{~nm}$ measured by the OLEX LIDAR on 9 March 1999 inbound and outbound from the eye of Davina. Black arrows mark 'jumps' in the anvil where cirrus clouds are detached from underlying convection.

directly into the eye of Davina and the Geophysica entered the cyclone in different areas, directly sampling clouds and trace gases.

\section{The measurements}

The backscatter intensity was measured by the upward pointing LIDAR in the central part of the cyclone at three wavelengths (namely 355, 532, and $1064 \mathrm{~nm}$ ) (Fig. 5). It is a common feature of many TCs to show a large cirrus deck above the storm which forms from moist planetary boundary layer air transported upward to the tropopause by deep cumulus convection. The shape of the cirrus deck reflects this process. The area above the central part of the storm is almost cloud free. This agrees with the general mean descent of dry air from the uppermost troposphere in the core of the storm. Right above the most active part of the storm we have observed the thickest cloud layer in accordance with the model of cloud top penetration into the tropical tropopause layer. In Fig. 5 the variability of the backscatter signal within the cyclone is evident. Only the backscatter intensity at $1064 \mathrm{~nm}$ is shown, because it penetrates the cirrus clouds and provides evidence of their upper boundary, while the other wavelengths are blocked. Owing to the very large backscatter intensity in the nearby cirrus clouds the signal is partly saturated, thus quantitative information can only be derived in selected regions of the eye wall. In the region close to the eye wall the backscatter intensity is wave-lengthindependent $\left(\beta_{532 \mathrm{~nm}} / \beta_{1064 \mathrm{~nm}} \approx 1\right)$ and strongly depolarising indicating the presence of large ice particles. Although we are not able to infer the actual radii of the ice particles from the measurements, they are in a general agreement with the overshooting hypothesis. Since the cirrus cloud layer is generated by the cyclone in a way similar to the way the anvils are generated by isolated thunderstorms, we may refer to it as the cyclone's 'anvil'.

The anvil model has found a general confirmation in the observation performed by the Tropical Rainfall Measurement Mission (TRMM) satellite three days before the overpass (not shown). In that case an area as large as $600 \mathrm{~km}^{2}$ was lying above the $14 \mathrm{~km}$ which is generally considered a good proxy for the lower boundary of the tropical tropopause layer (TTL). This large injection of planetary boundary layer air into the tropical tropopause layer by cumulonimbus clouds is a common feature of many TCS especially during their developing stage. This is, in fact, the period when it is more likely to observe large vertical wind speed.

Other clearly prominent features detected by OLEX are the 'jumps' in the cirrus deck. The most clearly visible one was located just above the position of the external part of the eye wall. The measurements made by OLEX indicate that this region is completely disconnected from the underlying convective activity. This feature extends around the cyclone. This may reflect the organisation of convection associated with the tropical cyclone. In opposition to the behaviour of a singular overshooting cloud, the tropical

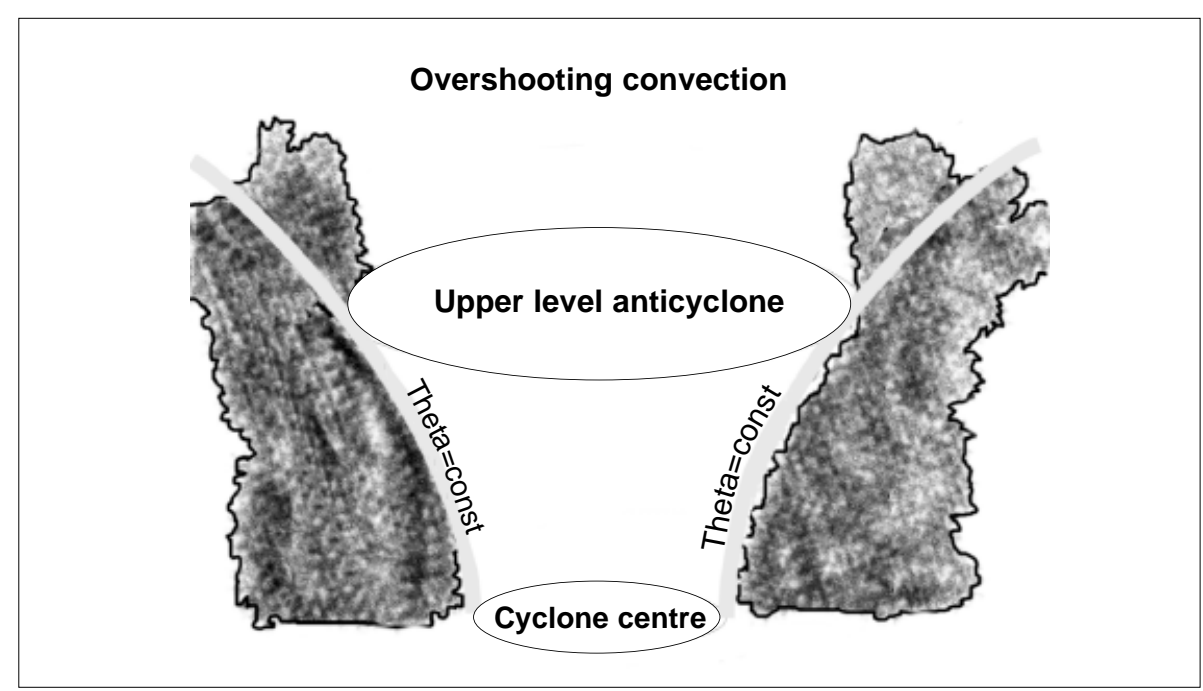

Fig. 6 A schematic structure of the upper part of a tropical cyclone. The thick grey lines indicate the shape of the isentropes. The residual part of the overshooting convection is spreading from the centre of the system following the isentropes. 


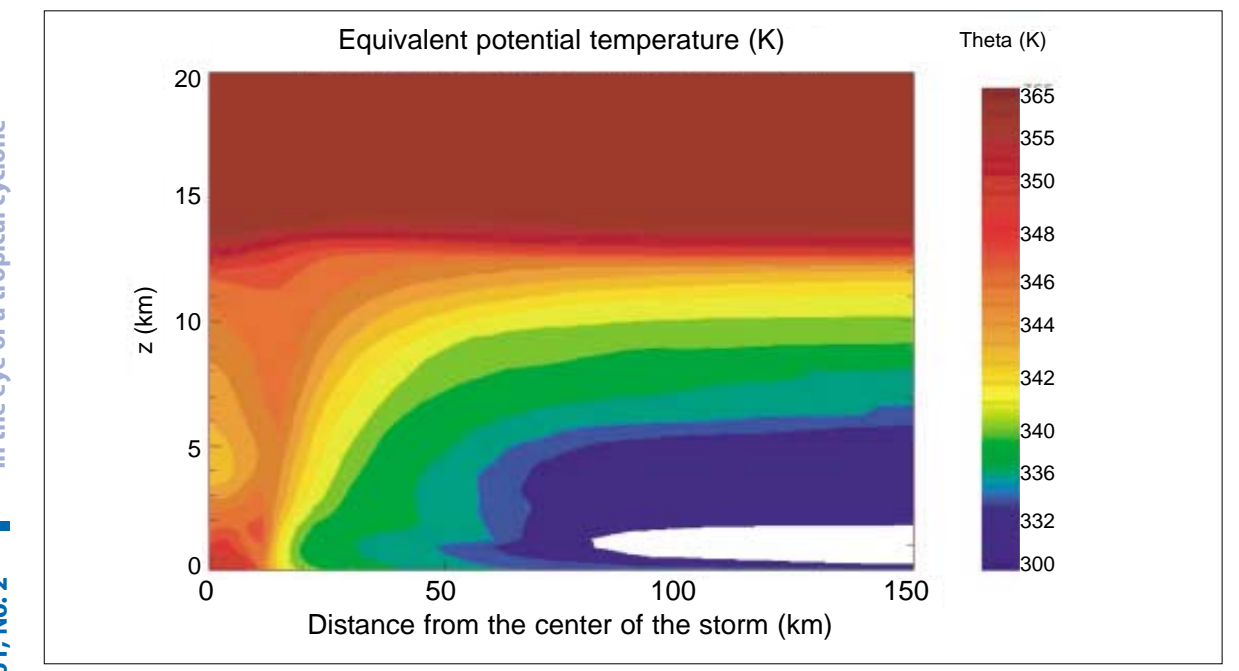

Fig. 7 The equivalent potential temperature cross-section of a tropical cyclone. The eye of the system is exhibiting an almost constant value of the theta while in the region close to the eye wall, the surface of constant equivalent potential temperature tend to assume the typical funnel shaped structure. The data has been obtained using the non-hydrostatic version of the cyclone model developed by Kerry Emanuel (1999).

cyclone seems to induce a coherent overshooting over a large scale.

We can assume that the air parcels above a tropical cyclone are moving along surfaces of constant equivalent potential temperature. This quantity, whose logarithm is proportional to the entropy of the moist air, is conserved along reversible moist-adiabats. In this kind of process the liquid water that condenses during an expansion is carried with the parcel. Figures 6 and 7 present the schematic structure and a plot of the equivalent potential temperature in the central part of a cyclone, respectively. The plot has been obtained using the idealised model of cyclone described by Emanuel 1999. Comparing Fig. 7 with Fig. 5 reveals that the central part of the storm, where OLEX detected the highest number of large particles, is the same area where the shape of the cirrus deck is not following the surface of constant entropy. The 'jumps', following this view, may be regarded as regions of recent overshoot.

\section{Conclusions and outlook}

During March 1999 two research airplanes collected measurements above and inside the eye of the tropical cyclone Davina. This was a unique opportunity to obtain information on the interaction between the tropical cyclone and the tropical tropopause layer. Although only very few observations have been performed above these devastating storms, in situ observations are crucial to assess their climatic importance. This is particularly true in the context of a change in $\mathrm{CO}_{2}$ would increase both, the number and the relative intensity of tropical cyclones, Knutson and Tuleya (2004), Emanuel (1987; 2005). According to the measurements acquired during the flight, a significant part of the convection embedded in the storm reached altitudes above the average cold point tropopause height measured during the campaign. The overall net moistening associated with the process crucially depends on the microphysical processes associated with the particles. These are known to be very size dependent. Large particles tend to fall rapidly, dehydrating the layer while smaller particles may evaporate humidifying the lower stratosphere. The dataset presented here is one of the few that we have on the interaction between the tropical cyclone and the tropical tropopause layer. Although the measurements taken by OLEX are of great interest we importance of these processes on a global scale. An important step toward a better understanding will be represented by the launch of a satellite based LIDAR named CALIPSO (www.calipso.larc.nasa.gov/). in climate. There is evidence that an increase need much more data to evaluate the

\section{References}

Chan, U. C. (2000) Tropical cyclone Davina:

its structure in relation to ozone

concentration. Environmental Science

Department, Lancaster University UK, graduate thesis

Dunlop, S. (2001) A Dictionary of Weather. Oxford Reference Online, Oxford University Press

Emanuel, K. (1987) The dependence of hurricane intensity on climate. Nature, 326, pp. 483-485

Emanuel, K. (1991) The theory of hurricanes. Annual Rev. Fluid Mech., 23 pp. 179-196

Emanuel, K. (1999) Thermodynamic control of hurricane intensity. Nature, 401, pp. $665-669$

Emanuel, K. (2005) Increasing destructiveness of tropical cyclones over the last 30 years. Nature, 436, pp. 686-688

Holton, J. R., Haynes, P. H., McIntyre, M. E., Douglass, A. R., Rood, R. B. and Pfister, L. (1995) StratosphereTroposphere exchanges, Reviews of geophysics, 33, 4, 8755-1209 (p. 403).

Knutson, T. R. and Tuleya, R. E. (2004) Impact of $\mathrm{CO}_{2}$-induced warming on simulated hurricane intensity and precipitation: Sensitivity to the choice of climate model and convective parameterization, J. Clim., 17 (18), pp. 3477-3495

Smith, R. K. (2000) The role of cumulus convection in hurricanes and its representation in hurricane models. Rev. Geophys., 38, pp. 465-489

Stefanutti, L., Mackenzie, A.R., Santacesaria, V., Adriani, A., Balestri, S., Borrmann, S., Khattatov, V., Mazzinghi, P., Mitev, V., Rudakov, V., Schiller, C., Toci, G., Volk, C.M., Yushkov, V., Flentje, H., Kiemle, C., Redaelli, G., Carslaw, K.S., Noone, K. and Peter, T. (2004) The APETHESEO tropical campaign: An overview, J. Atmos. Chem., 48, pp. 1-33

Wirth, M. and Renger, M. (1996)

Evidence of large-scale ozone depletion within the arctic polar vortex 1994/1995 based on airborne lidar measurements. Geophys. Res. Lett., 23, pp. 813-816

Correspondence to: Dr Carlo Buontempo, Met Office, FitzRoy Road, Exeter EX1 3PB. e-mail: carlo.buontempo@metoffice.gov.uk (c) Crown copyright, 2006

doi: 10.1256/wea.87.05 